\title{
Model Antrian Dengan Pengalihan Dinamis untuk Mengurangi Kemacetan JALAN RAYA
}

\author{
The Queuing Model With Dynamic Redirect to Reduce The Highway Traffic \\ JAM
}

\author{
${ }^{1}$ Erwin Harahap, ${ }^{2}$ Icih Sukarsih, ${ }^{3}$ Farid H.B., ${ }^{4}$ M. Yusuf Fajar \\ ${ }^{1,2,3,4}$ Fakultas MIPA, Universitas Islam Bandung, Jl. Tamansari No. 1 Bandung 40116 \\ e-mail: ${ }^{1}$ erwin2h@unisba.ac.id, ${ }^{2}$ sukarsh@unisba.ac.id, ${ }^{3}$ faridhb@unisba.ac.id, \\ 4myusuffajar@unisba.ac.id
}

\begin{abstract}
This study examines the impact of the dense of transportation line in highway such as severe traffic and a very long queue of vehicles. The solution to this problem is to adjust dynamically the queue length at each point of intersection in a balanced manner. The model used is the stochastic model into a queue of vehicles with the arrival rate is determined based on the Poisson distribution and service at the intersection points based on exponential distribution. Demonstration of dynamic queuing model shown by simulation using SimEvents MATLAB-Simulink. The results of the simulation showed that the dynamic queue mode can minimize the impact of density of vehicles more regularly than using the conventional method.
\end{abstract}

Keywords: queuing models, simulation, simevents, Simulink, traffic jam, toll brexit

\begin{abstract}
Abstrak. Penelitian ini mengkaji dampak dari padatnya alur transportasi jalan raya berupa kemacetan parah dan antrian kendaraan yang sangat panjang. Solusi dari masalah ini adalah dengan mengatur panjang antrian secara dinamis pada tiap-tiap titik persimpangan secara seimbang. Model yang digunakan adalah model stokastik pada antrian kendaraan dengan tingkat kedatangan ditentukan berdasarkan distribusi Poisson dan pelayanan pada titik-titik persimpangan berdasarkan pada distribusi eksponensial. Demontrasi dari model antrian dinamis ditunjukkan dengan simulasi menggunakan SimEvents MATLAB-Simulink. Hasil dari simulasi menunjukkan bahwa mode antrian dinamis dapat meminimalisir dampak kepadatan kendaraan yang lebih teratur dibandingkan dengan menggunakan cara konvensional.
\end{abstract}

Kata kunci: model antrian, simulasi, simevents, Simulink, kemacetan, tol brexit

\section{Pendahuluan}

Kondisi lalu lintas perkotaan khususnya kota-kota besar misalnya di kota Bandung, hingga saat terjadi perkembangan sarana transportasi yang pesat, baik secara kualitas maupun kuantitas. Perkembangan secara kualitas dapat dilihat dari kendaraan bermotor yang dari tahun ke tahun selalu mengalami perubahan dalam bentuk maupun sistem mesinnya. Secara kuantitas, jumlah kendaraan bermotor juga mengalami kenaikan.

Berdasarkan data terkini, laju pertumbuhan kendaraan bermotor di kota-kota besar di Indonesia termasuk di kota Bandung, setiap tahunnya mengalami kenaikan 
dikisaran 14 hingga 15 persen. Jika laju pertumbuhan kendaraan baru di kota Bandung sudah tinggi, maka jumlah kendaraan bermotor sudah over load. Jumlah kendaraan bermotor berplat D di kota Bandung pada tahun 2010 mencapai 1,15 juta kendaraan, pada tahun 2011 tercatat 1,27 juta kendaraan, kemudian pada tahun 2012 naik menjadi 1,43 juta kendaraan. Sementara itu, untuk tahun 2013 jumlah kendaraan bermotor di Kota Bandung mencapai lebih dari 1,6 juta kendaraan. Perbandingan jumlah kendaraan bermotor setiap tahunnya mobil 15 persen sedangkan motor 85 persen dari jumlah total kendaraan.

Meningkatnya daya beli masyarakat terhadap kendaraan bermotor memicu meningkatnya jumlah kendaraan bermotor. Hal inilah yang menjadi salah satu alasan terjadinya kemacetan ataupun kecelakaan lalu lintas. Berdasarkan Manual Kapasitas Jalan Indonesia, meningkatnya kemacetan pada jalan perkotaan maupun jalan luar kota diakibatkan bertambahnya kepemilikan kendaraan, terbatasnya sumber daya untuk pembangunan jalan raya, dan belum optimalnya pengoperasian fasilitas lalu lintas yang ada. Hal ini merupakan persoalan utama di banyak kota.

Permasalahan kemacetan ini tidak bisa dibiarkan dan perlu langkah-langkah untuk mengatasinya. Solusi awal yang dapat dilakukan adalah dengan melebarkan jalan raya, namun hal tersebut memerlukan dana yang sangat besar. Selain itu jalan raya yang terbatas, tidak mungkin lagi untuk diperlebar. Salah satu alternatif solusi dari masalah kemacetan adalah pengaturan rambu lalu lintas berupa lampu lalu lintas atau pengalihan alur transportasi kendaraan.

Pada artikel ini akan dibahas mengenai model pengalihan pada antrian kendaraan secara dinamis untuk mengurangi kemacetan dengan memperhatikan beberapa faktor tertentu seperti panjang antrian, hambatan-hambatan, dan alternatif rute perjalanan. Hambatan-hambatan perjalanan yang umum ditemui adalah persimpangan jalan, pintu tol, penyempitan jalan, kecelakaan, dan antrian di SPBU atau pom bensin.

\section{Latar Belakang dan Motivasi}

Peristiwa kemacetan jalan raya yang cukup fenomenal adalah panjangnya antrian kendaraan di pintu tol keluar brebes timur (Brexit) yang mencapai $20 \mathrm{Km}$ lebih. Berdasarkan pada paparan diberbagai media masa mengenai kemacetan di Tol Brexit, peneliti tertarik untuk mengkaji penyebab dari antrian panjang tersebut, dampak yang ditimbukan, serta alternative solusi agar peristiwa yang sama dapat dihindari dimasa depan. Faktor-faktor yang dianalisis dalam artikel ini adalah titik-titik penghambat antrian, pengalihan alur kendaraan untuk meminimalisir antrian, dan.

Penyebab kemacetan yang terjadi di pintu keluar tol Brebes (Brexit) adalah sedikitnya jumlah pintu keluar, dan menumpuknya antrian di SPBU. Kondisi ini membuat jumlah kendaraan menumpuk karena hambatan di pintu keluar dan titik penghubung jalan tol dan arteri. Dilain pihak, jumlah kendaraan yang masuk sangat banyak ke arah Tol Pejagan-Brebes.

Dari Cikarang sampai Cikopo tidak ada kemacetaan kendaraan, begitu pula Dari Kopo sampai Kanci juga tidak ada kemacetan, namun setelah Kanci baru muncul kemacetan. Hal ini terjadi karena di Cikarang Utama terdapat 35 pintu tol, sementara di 
di Pejagan-Brebes Timur hanya ada lima keluar. Setelah kendaraan keluar dari tol Brebes Timur, terjadi kepadatan karena pertemuan dengan jalur Pantai Utara Jawa (Pantura). Akibatnya, terjadi antrian kendaraan di pintu keluar Tol Brebes Timur. Alternatif solusi yang dapat diambil adalah agar para pengguna jalan tidak hanya menggunakan jalur tol untuk menuju Jawa Tengah. Terdapat beberapa jalur alternatif yang dapat digunakan untuk mengurangi kepadatan kendaraan di tol. Misalnya, dari arah Cikopo ke pantura, karena Simpang Mutiara-Jomin dinilai masih lengang. Selain itu masyarakat yang ingin mudik ke Jawa dapat juga menggunakan jalur tol yang lama sebelum ada tol Cipali.

\section{Model Antrian dengan Pengalihan Dinamis}

Menyikapi dari terjadinya kemacetan di pintu tol Brexit yang menimbulkan banyak kerugian, diharapkan dimasa depan kejadian tersebut, baik di pintu keuar tol maupun di lokasi jalur transportasi lainnya dapat dihindari. Pada artikel ini kami mengajukan salah satu alternatif solusi untuk penyelesaian masalah kemacetan di pintu tol Brexit dengan menggunakan metode pengalihan dinamis. Melalui metode ini diharapkan antrian pada tiap-tiap titik hambatan dapat diminimalisir atau disebar secara seimbang di berbagai lokasi jalur alternatif.

Gambar 1 menunjukkan peta jalur perjalanan menuju lokasi jawa tengah yang bermuara di pintu tol Brexit, disertai dengan beberapa jalur alternatif.

\section{Simulasi dan Hasil Penelitian}

Model pengalihan antrian secara dinamis untuk menghindari terjadinya kemacetan di pintu tol Brexit kami implementasikan dalam bentuk simulasi menggunakan SimEvents MATLAB. Kami rancang rute perjalanan dengan titik awal dari arah jawa barat menuju jawa tengah menggunakan jalur Tol Cipali dan beberapa jalur arteri.

Pada simulasi ini, kami asumsikan bahwa seluruh pengguna jalan bermaksud menggunakan jalur Tol Cipali karena pertimbangan waktu perjalanan yang lebih cepat dan nyaman. Untuk mengurangi kemacetan di pintu Tol Brexit, kami simulasikan model pengalihan pengalihan antrian secara seimbang ke beberapa jalur alternatif.

Berdasarkan hasil simulasi diperoleh hasil yang cukup signifikan. Kami bandingkan hasil simulasi keadaan jalur tol Pejagan-Brebes Timur dengan implementasi model yang kami ajukan dan tanpa implementasi model. Melalui penerapan metode serta algoritma yang tepat sebagai parameter untuk pengalihan kendaraan ke jalur-jalur alternatif, antrian kendaraan diberbagai jalur terindikasi seimbang. Dengan demikian model antrian dengan pengalihan dinamis, secara simulasi telah berhasil menghindari terjadinya kemacetan panjang di pintul tol Brexit yang telah menelan 12 korban jiwa meninggal dunia. 


\section{Kesimpulan dan Saran}

Kemacetan merupakan dampak dari tidak seimbangnya ketersediaan sumber daya dibandingkan dengan para pengguna jalan, dimana jumlah alat transportasi lebih besar dibandingkan dengan media jalan raya. Namun dapat juga kemacetan ini ditimbulkan oleh kurang efektifnya manajemen yang diterapkan oleh pengelola dalam hal ini pemerintah. Oleh arena itu, pengelolaan lalu lintas yang tepat dapat mengurangi terjadinya kemacetan dan menghindari akibat-akibat yang merugikan.

Model pengalihan dinamis untuk mengurangi antrian kemacetan kami implementasikan pada peritiwa kemacetan panjang di pintu Tol Brexit. Hasil yang diperoleh adalah bahwa dengan pengaturan pengalihan yang dinamis, berdasarkan simulasi yang telah kami lakukan, kemacetan di pintu tol Brexit dapat dihindari dengan menyeimbangkan sebaran kendaraan ke beberapa jalur alternatif.

Beberapa alternatif solusi lainnya dapat diterapkan untuk menghindari kemacetan dijalan raya, misalnya dengan memberikan jalur khusus pemotor di jalan Tol, atau menggunakan digital sensor pada kendaraan sehingga dapat mengurangi waktu transaksi.

\section{Daftar pustaka}

Direktorat Jenderal Bina Marga (1997). Tata Cara Perencanaan Geometrik Jalan Antar Kota, Jakarta. Tersedia: https://id.wikibooks.org/wiki/Rekayasa_Lalu_Lintas/Karakteristik_kendaraan September 2016]

Badan Pengatur Jalan Tol (2016). Kementerian Pekerjaan Umum dan Perumahan Rakyat. Tersedia: http://bpjt.pu.go.id/spm [29 September 2016]

Shears, R. (2016). Is this the world's worst traffic jam? Fifteen motorists die in three days after getting caught in gridlock at Indonesian junction... named BREXIT. [Online]. Tersedia: http://www.dailymail.co.uk/news/article-3678467/Is-world-sworst-traffic-jam-Fifteen-people-die-getting-caught-gridlock-Indonesian-junctionnamed-BREXIT.html 